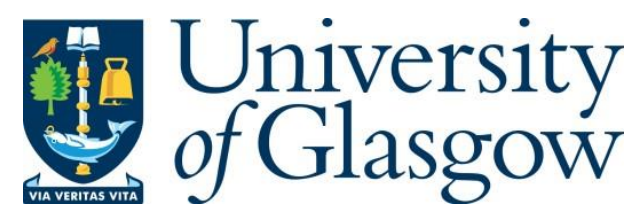

Campbell, A. (2019) Atlantic exchanges: the poetics of dispersal and disposal in Scottish and Caribbean seas. Journal of Postcolonial Writing, 55(2), pp. 195-208.

There may be differences between this version and the published version. You are advised to consult the publisher's version if you wish to cite from it.

$\underline{\text { http://eprints.gla.ac.uk/227881/ }}$

Deposited on: 14 January 2021

Enlighten - Research publications by members of the University of Glasgow http://eprints.gla.ac.uk 


\title{
Atlantic exchanges: The poetics of dispersal and disposal in Scottish and Caribbean seas
}

\author{
Alexandra Campbell* \\ The University of Edinburgh, Edinburgh, Scotland
}

*Email: alexandra.campbell@ed.ac.uk

Abstract:

This article offers a series of readings of poets from both sides of the Atlantic Ocean whose works respectively make visible the otherwise invisible and offshore narratives of marine waste that currently circulate within the world's oceans. Through a comparative archipelagic reading of Scottish and Caribbean poets this article examines the different forms of cultural and material exchange that proliferate through the 'heavy waters' (DeLoughrey 2010) of the Atlantic. From stones and bones to plastic dolls and rubber ducks, the poetic encounters with marine waste in the works of Édouard Glissant, Kamau Brathwaite, Derek Walcott, Kei Miller, Jen Hadfield and Kathleen Jamie provide a means through which to access and critique transoceanic networks of colonial and capital exploitation. The manifestation of waste across these works gives rise to a poetics of salvage and recycling that corresponds with a distinctly environmental ethics of relation as driven by the ocean. Keywords: Archipelagic studies; Blue Humanities; marine plastics; Caribbean poetry; Scottish poetry

Across the archipelagos of the Atlantic, poetic encounters with marine waste provides a means through which to access and critique the networks of capitalist and colonial exploitation that currently circulate within the world's oceans. This article offers a series of readings of poets from both sides of the Atlantic Ocean whose works respectively make visible the otherwise invisible and offshore narratives of marine waste that currently circulate within the world's oceans. Across the works of Caribbean authors such as Édouard Glissant, Kamau Brathwaite and Derek Walcott, the topographic contours of the Caribbean archipelago serve as a means through which to imagine new modes of relation and connection across island spaces. It will suggest that the acts of salvage, restoration and recirculation enacted by their respective poetic engagements with the Caribbean archipelago can be fruitfully applied to archipelagic literatures emerging from across the other side of the Atlantic, namely in Scotland. 
In recent years the cluster of islands geographically referred to as the "British Isles"1 has begun to attract new archipelagic readings of place. The adoption of the term "archipelagic" within contemporary literary and historical scholarship of the British Isles is important, as it addresses questions of national identity, cultural connection and belonging through more plural, neutral and relational terms than have previously been available. By encouraging a form of history and culture that is "pelagic, maritime and oceanic into which an extraordinary diversity of cultural and other movements has penetrated deeply" (Pocock 2005, 78), archipelagic perspectives are becoming increasingly influential when examining the cross-cultural connections and transnational dimensions evident within what is generally referred to as "British and Irish Literature", which of course includes a variety of Scottish, English, Welsh, Irish and Northern Irish texts. The adoption of archipelagic perspectives allows scholars to explore the "long, braided histories played out across the British-Irish archipelago", thus circumventing the usual "Anglo-centric and Victorian paradigms" loaded into terms such as the "British Isles" or "British Literature" (Kerrigan 2008, 2). Importantly, the adoption of such archipelagic frameworks not only encourages new readings of transnational relation between Scotland, Ireland, England and Wales, but

reinvigorates the meaning of ocean water, [where the] archipelago's transoceanic scope invites comparison with the Caribbean, that other 'group of islands' on the other side of the Atlantic, in a manner that connects to the figurative possibilities of water found in Walcott and Brathwaite's seascapes. (Morris 2015, 55)

As this article will show, these transoceanic interconnections between Scotland and the Caribbean are not only found in the cultural and historical movements of migrants and slaves 
across the Middle Passage but are increasingly traced through the transoceanic movements of marine waste. ${ }^{2}$

For Elizabeth DeLoughrey (2010), "Caribbean writers have long been concerned with the heavy waters of ocean modernity and have [often] rendered waste in terms of pollution as well as the wasted lives of slaves and refugees" (708). In the works of Glissant, Walcott and Brathwaite, their respective encounters with the various cultural, historical and material flotsam of the Atlantic Ocean disrupts the classic western configuration of the sea as a space that is characteristically void of human history. Yet, while the majority of their works are concerned with giving voice to the submerged human histories of the Atlantic, attending to those "wasted lives" of the Middle Passage (DeLoughrey 2010, 708), their works also draw attention to the circulation of various waste materials that bare the traces of both cultural and environmental catastrophe. Across their works, Glissant, Brathwaite and Walcott engage with acts of salvage and restoration through the trope of beachcombing in which the accumulation of various waste materials at the shoreline aligns vividly with the poetic recovery of submarine histories.

Whereas the gathering of fragments at the shoreline aligns with narratives of cultural restoration and regrowth in the Caribbean, for poets on the other side of the Atlantic the encounter with marine debris provides access to pressing concerns regarding a growing consciousness of global environmental crises as evidenced through the transnational flow of plastic debris. While arguably Caribbean encounters with marine debris align with anxieties regarding violent colonial pasts, for the Scottish authors discussed in the second half of this article, encounters with oceanic waste materials align with a growing anxiety regarding precarious environmental futures. Their poetic exploration of marine waste engages with similar questions of temporality and relationality at sea but transforms the Caribbean interest in the histories of dispersal into fascination with the politics of disposal. Through their 
accumulation of a range of marine materials including bird-skulls, plastic dolls, bottles, rubber ducks and nylon rope, the works of the contemporary poets Kei Miller, Jen Hadfield and Kathleen Jamie contend with damaging cultural constructions of the ocean as a site "so vast and powerful that anything dumped into it will be dispersed into oblivion" (Alaimo 2012, 477). Across the works of Scottish and Caribbean poets, the Atlantic Ocean emerges as both a reservoir of human history, and an archive of anthropogenic harm.

The work of Miller, in particular, serves as a crucial connective thread between these archipelagic literatures. His 2014 collection The Cartographer Tries to Map a Way to Zion consciously explores the colonial resonances of transatlantic history through a series of dialogic poems embark upon on a transoceanic voyage from Jamaica's Bloody Bay to Edinburgh Castle. The collection explores itinerant modes of relation and hybrid forms of belonging in both Scotland and the Caribbean in an attempt to navigate his own cross-cultural relationships with these two Atlantic archipelagos. Miller's works are generally concerned with the ways in which West Indian immigrant figures navigate "the strange new places in which they find themselves" (Scottish Book Trust n.d.). In a short piece for The International Journal of Scottish Literature, Miller works to map out the coordinates of his own "strange place" between Scotland and Jamaica, remarking that "in me and my biography there is now an undeniable Scottish-Caribbean Connection" $(2008,1)$. While the question of identity and integration is central to The Cartographer, I argue that Miller's exploration of the ocean as a site of material exchange and colonial encounter extends preoccupations with narratives of migrant dispersal into pressing questions of contemporary waste disposal at sea. Using Miller's text as a connective bridge between the ensuing discussions of Caribbean and Scottish poetry, I will interrogate the extent to which the Atlantic Ocean can be understood as a site of temporal collision between "two drastically distinct timeframes", where the poetic 
encounter with marine debris in Modern Scottish and Caribbean texts enables an engagement with both violent colonial pasts, and disturbingly toxic futures (Longobardi 2014, 181).

\section{Atlantic "tidalectics"}

Within Caribbean writing the sea is not viewed as a cordon sanitaire, an empty or metaphorical zone, but is instead understood as both a material and metaphysical medium through which new "worlds" are exposed to one another and brought into a productive "poetics of relation in which each and every identity is extended through a relationship with the Other" (Glissant 1997, 11). For Glissant, this extension of identity draws upon the interconnected topographies and colonial geographies of the Caribbean, in which the islands are not viewed in isolation but are understood as physical and cultural spaces that are inherently interactive and responsive to one another: "each island embodies openness. The dialectic between inside and outside is reflected in the relationship of land and sea. It is only those who are tied to the European continent who see insularity as confining" $(1989,139)$. Across his critical and creative works, Glissant cultivates a model of archipelagic relation that contravenes colonial narratives of maritime space. His proposed "poetics of relation" follows both geographical and historical currents of travel, trade and transmigration, and it encourages the pursuance of a dynamic model of history in which marine environments are central to ongoing forms of cultural and material exchange.

Responding to the colonial politics of maritime disposal and dispersal, Glissant's "poetics of relation" engages with the violent histories and environments of "rupture and connection" $(1997,151)$ that wind their way across the Caribbean, and actively seeks to restore the fragmented and dispersed communities of the archipelago through a "literature [that] is not only fragmented, it is henceforth shared" (Glissant 1989, 77). This mode of poetic rejuvenation emerges frequently through the trope of beachcombing. In a short essay 
titled "The Black Beach", Glissant adopts the position of a nomadic beachcomber strolling on the shores of Le Diamant on the southern coast of Martinique. Throughout this piece, the ecological dynamism of the island environment comes to influence Glissant's "rhizomatic"3 discourse in which the chaotic interrelation of shore, sand and soil becomes emblematic of his "poetics of relation":

Branches of manchineel and seagrape lie about in havoc, writing in the more peaceful sunlight a memoir of the night sea's work. Brown seaweed piled there by the invisible assault buries the line between sand and soil. Uprooted coconut palms have tumbled sideways like stricken bodies. Along their trail, all the way to the rocky mound marking the distant Morne Larcher, one can sense the power of a hurricane one knows will come. $(1997,121)$

Defined as a site of contact and exchange between nature and culture, for Glissant the "rhythmic rhetoric of a shore" possesses a seductive "circularity" that is able to overcome the constrictive framing of colonial narratives of time and place $(1997,122)$. For Glissant, the productive chaos of the shoreline which is always "directly in contact with everything possible" gives rise to a relational model of history and culture that senses, assumes, opens, gathers, scatters, continues and transforms $(1997,121,32,94)$. Across the essay, the "havoc" wreaked by tide and hurricane is transformed from a destructive force into a productive sense of relation, destabilising binary constructions of land and sea as well as colonial ideologies of containment and control.

In opposition to cultural models of fixity and continuity, the changing dimensions of land and sea in Glissant's works provide a means through which to consider the relationship between narratives of production and destruction within Caribbean writing. As Sonya 
Postmentier (2017) has recently argued, the experience of "cultivation" and "catastrophe" is key to the Caribbean imaginary, where the forces of tide and hurricane and their attendant "catastrophe yield $[\ldots]$ to the cultivation -- and the collection -- of art" (182). For Glissant, environmental catastrophe is central to the Caribbean experience, which is not characterized by "the economy of the meadow [or the] serenity of the spring" but rather by "the irruption into modernity" $(1989,146)$. This sense of irruption brings with it an attendant sense of chaos and fragmentation that is incompatible with western discourses of history and linear progress. This relationship between chaos, cultivation and collection is particularly important in the work of the Barbadian poet Kamau Brathwaite, whose frequent invocation of the hurricane and fascination with fragmentation provides an opportunity to consider "the interconnectedness of environmental and cultural experience" as enacted at the shoreline (Postmentier 2017, 182). Positioned as the site of arrival and departure, wreckage and relation, the shoreline is presented as "the ultimate frontier", a space that bares "visible evidence of our past wanderings and our present distress" (Glissant 1989, 11). Invoking lines from Walcott's "The Sea is History" ("Where are your monuments, your battles, martyrs? / Where is your tribal memory?" [Walcott 2014, 253]), Glissant attests that "landscape is its own monument" whose "meaning can only be traced on the underside. It is all history" $(1989,11)$. As the site of various material surfacings, the shoreline becomes the site upon which these subterranean and submarine histories can become visible, and through poetry, newly legible.

Yet, for Glissant it is not only the terrestrial beaches that emerge as sites of crosscultural contact and historical exchange, but the ocean itself. Bringing "to light like seaweed, these lowest depths, these deeps" (Glissant 1997, 6) that harbour the submerged voices of the Middle Passage, his poetics exhibits a concern with both "material residue of the past as well as the lost lives of transoceanic subjects" (DeLoughrey 2010, 704). His work drives the 
establishment of an environmental ethic within archipelagic writings that is responsive to histories of transoceanic voyages, submergences and wreckages. In the preface to Poetics of Relation he opens his discussion with two quotations that direct our attention towards the oceanic imaginary of Caribbean literature: "Sea is History" (Derek Walcott) and "The unity is sub-marine" (Edward Kamau Brathwaite) (Glissant 1997, vii). For Glissant, the Ocean is not an empty void, but is instead viewed as the site of Atlantic modernity whose "vast beginning $[\ldots]$ is marked by [ ... ] balls and chains gone green" (6). The striking image of the "scarcely corroded balls and chains" that punctuate the seafloor of the Atlantic stands both as monument to the victims of the transatlantic slave trade and as a testament to the sea's transformative temporalities (6). Within Glissant's writings the ocean is not an end point, but an origin. It is the site of strange movements and meetings between the past, the present and possible futures.

As DeLoughrey suggests, Caribbean writing is frequently drawn to the plurality and "the infinity of the oceanic imaginary [which] provides an alternative model of space and time, a 'tidalectic' between past and present, land and sea, the local and the global' (2012, 803). The concept of the "tidalectic" was first coined by Brathwaite, whose poetic attention to Caribbean histories and geographies explicitly draws upon the complex relationship between maritime space and cultural production. Engaging the elemental forces of tide and hurricane, Brathwaite's "tidalectic" places emphasis on the open-ended and cyclical action of the ocean in which land and sea, arrival and departure, local and global are brought into a state of continuous contact and exchange. Rather than adopting the image of the single wave (often attached to "waves" of colonisation), Brathwaite's tidalectic draws from the dynamism of "the ripple and the two tide movement" (quoted in Naylor 1999, 145). The inclusion of "ripple" and "two tide" is significant here as it ensures that the tidalectic is not simply a dichotomous process of infinitely repeated motions of arrival and departure enacted between 
two static points but is instead characterized by an ongoing "tangled urgent meaning to $\&$

fro. like foam. saltless as from the bottom of the sea. dragging our meaning our moaning/song from Calabar along the sea-floor sea-floor with pebble sound $\&$ conch $\&$ wound \& sea-sound moon" (Brathwaite quoted in Naylor 1999, 162; bold in original). Describing the "pebbles \& plankton $\&$ memories $\&$ the shale that is like a low / moan now. out out towards a new meaning out there" (162), Brathwaite draws a sense of continuous relation between the sunken history of the Middle Passage, the sea-sounds of the islandscape and the voices of the island community. The constant tug and pull of the tide unearth the sounds of "pebble", "conch \& wound", reclaiming a cacophony of drowned voices that fell to the "bottom of the sea" during the passage from Calabar in Nigeria to "a simple unsuspecting shop in Mile\&Q, Barbados” (162). In a similar mode to Glissant's beachcombing, Brathwaite's tidalectic enacts a poetics of salvage and restoration that works to recover and recirculate the submerged voices and histories of the Atlantic.

For Mandy Bloomfield (2016), Brathwaite's sensitivity towards the topographies and geographies of the Caribbean archipelago gives rise to an "archaeopoetic" (153) engagement with place, history, and culture. Described by Brian McHale as "poetry of stratification and excavation, of fragments and ruins" (quoted in Bloomfield 2016, 5), the concept of “archaeopoetics" that Bloomfield goes on to present sees Brathwaite's work in relation to archaeological acts of mining and excavation. Yet in the context of Brathwaite's oceanic imaginary, this sense of excavation might better be understood in relation to acts of gleaning, salvaging and recycling at the shoreline. As Bloomfield suggests, Brathwaite's tidalectic is not only attached to submerged colonial narratives of arrival and departure but is also attached to the wider "dynamic between catastrophe and salvage, damage and regeneration" (180). In the poem "Fragments: Fetish" this dynamic between catastrophe and salvage is further enacted through an engagement with themes of disintegration and restoration. Across 
the poem Brathwaite presents the island landscape as a fragmented and tempestuous space formed from the accumulation of various shards, "splinters", "torn up roots / broken box- / es, ruins" (Brathwaite 1995, 12). Yet while these images are fragmentary in nature, Brathwaite reminds us that

The objects of wood, thatch and stone, decayed relics, splinters, shell are a journey contemplation restores them to our time makes once more the oar, fossil's bone, the fetish of our worship

Across the poem, Brathwaite mediates a sense of ruin, fragmentation and decay with the possibility of restoration. In gathering together the various strands, shards and splinters of history and culture that have washed ashore, the poem seeks to address past narratives of "struggle" and conquest that have shaped the Caribbean, and in doing so gives rise to the possibility of "restoration" and recovery (11). The poem's repetition of "out of the" establishes a new order out of the wreckage of the beachscape, where "out of the ruins", "out of the cracks", "out of the silence" new voices and images might begin to grow (12).

Interrogating the "border between the disposable and the enduring" (DeLoughrey 2010, 709), Brathwaite's poems enact an ethics of recycling and recuperation. In "Fragments", the poet's collection of various scraps of marine waste mimics the actions of a beachcomber who walks at the shoreline in search of items of value. As Tobias Döring (2015) has suggested, the act of beachcombing within Caribbean poetry can be interpreted as a "cultural labour" that "attempts to recreate some kind of order by assembling random bits 
and pieces lost as the result of maritime catastrophes" which can then be "reassembled for new purposes and provisionally reintegrated in different ways" (116). In "Fragments" Brathwaite gathers together various fragments that have washed ashore from a range of dislocated places across the archipelago, and actively reforms and reorders these pieces into a “journey" through both space and time $(1995,11)$. His creation of new narratives "out of" the wreckage of cultural catastrophe establishes a new narrative of "contemplation" and growth that is transposed against the "ravages" and "ruins" of the colonial world order (12). Importantly, this sense of growth and restoration does not simply align with the creation of a new complete and hegemonic "whole", but rather draws attention to the dynamic interpenetration of fragments that can be endlessly reordered into new productive relational arrangements.

In his 1992 Nobel Lecture, the St. Lucian poet Derek Walcott describes the history and culture of the Caribbean as that of a shattered vase whose various "African and Asiatic fragments" are spread across the archipelago. For Walcott the "gathering of broken pieces is the care and pain of the Antilles [where] Antillean art is this restoration of our shattered histories, our shards of vocabulary, our archipelago becoming a synonym for pieces broken off from the original continent" (1992, n.p.). The image of the fragmented archipelago echoes Brathwaite's configuration of Caribbean genesis in "Calypso":

The stone had skidded arc'd and bloomed into islands

Cuba and San Domingo Jamaica and Puerto Rico

Grenada Guadeloupe Bonaire

curved stone hissed into reef wave teeth fanged into clay white splash flashed into spray 


\section{Bathsheba Montego Bay}

(Brathwaite 1981, 48)

The form of the poem plays with the relational dynamics of fragmentation, where the use of stanzas and caesura crafts a sense of necessary interconnection that links the distinct island spaces through shared topographies and soundscapes. The poetic arranging of these island fragments does not follow any sense of cartographic or historical ordering but rather follows the rhythms of sound and sea. For Walcott, the "fragmented memory" is central to Caribbean literary production in which the "making of poetry" should not be understood as a process of "making" but of "remaking", a poiesis of salvage and restoration (1992, n.p.). This sense of "remaking” echoes with Döring's reading of beachcombing-as-bricolage, in which the collection of different waste materials and "literary flotsam" at the shoreline cultivates a form of "cultural production which is always a kind of cultural production already: recycling, imitating, improvising and inventing by means of debris washed ashore from shipwrecks" $(2015,117)$. In linking the site-specific practices of beachcombing to the modernist tradition of bricolage, Döring aligns Caribbean poetics with "a special kind of creativity that lies in reusing lost wreckage" where the arrival of waste products onshore brings with them "a profane genesis of newness" through their subsequent reordering and reintegration within the Caribbean imaginary (118). The sea and shore are not void of history but are instead figured as both poetic and historical origin.

Despite their poetic oppositions, for both Brathwaite and Walcott the experience of fragmentation is central to their practices in which disintegration is not viewed as ruination, but is instead positioned as a generative force of becoming -- each shard or splinter carrying within it the seed of possible futures. ${ }^{4}$ The continued accumulation of fragments at the shoreline across the works of Glissant, Brathwaite and Walcott aligns with "a poetics of survival, repair, and generation" (Postmentier 2017, 3), where through acts of salvaging their 
works reconstitute waste materials into a new economy of cultural production that is driven by an ethical impulse of restoration, rejuvenation and regrowth.

\section{Archipelagic plastics}

Where Glissant's, Walcott's and Brathwaite's encounters with the Atlantic are framed through narratives of fragmentation as demarcated by the "wasted lives in the Middle Passage and by the 'balls and chains gone green' that mark ocean history" (DeLoughrey 2010, 708), contemporary poetry emerging from the other side of the Atlantic has begun to express a related concern with narratives of dispersal and disposal as mediated through encounters with marine plastics. Whereas Caribbean narratives highlight the humanization of the ocean through "inscriptions of wasted lives in the Middle Passage" (DeLoughrey 2010, 708), the prevalence of marine plastics within Scottish poetry registers a different system of oceanic disposal and dispersal that configures the Atlantic as a "humanized technoscape that places new demands on our eating and disposal habits and also on our relation to literature" (Yaeger $2010,530)$.

In his collection The Cartographer Tries to Map a Way to Zion, the Jamaican poet Kei Miller (2014) contemplates the transoceanic voyage of "28,000 Rubber Ducks" that have been "sailing now since 1992" (53). The poem refers to an incident in 1992 when a ship off the coast of Hong Kong lost a container overboard containing 28,800 plastic bath toys, including 7,200 rubber ducks. The distribution of these "Friendly Floatees" across the global ocean has aided oceanographers such as Curtis Ebbesmeyer in mapping the flow and circulation of currents, and have further aided scientists who are currently studying the vast plastic gyres in the Pacific and Atlantic oceans. Since their initial wreckage in 1992, these synthetic creatures have been located across the globe from the frozen reaches of the Arctic to the coast of Maine, and in 2003 one washed up on the shores of the Hebrides. Miller's 
poem celebrates the voyage of the ducks who "knew to break free from dark hold of ships" and in so doing contrasts the diasporic narratives of black bodies across the Atlantic with the "unsqueezed" bodies of the "bright yellow dots that crest the waves / like spots of praise" (53). Here Miller uses the bodies of rubber ducks to link and critique colonial and capitalist networks of circulation and commodity production. As Alan Rice (2017) has suggested, the poem works to "commemorate the 'throwaway people' of the Middle Passage and of subsequent exploitative postmodern economic geographies" (264). In drawing together narratives of dispersal and disposal, Miller's poem presents a different narrative of oceanic salvage to those of Glissant, Brathwaite and Walcott, one that is not only conscious of colonial histories, but is wary of the neo-colonial flows of contemporary capital. The poem enacts a playful and powerful recalibration of the Caribbean beachcombing trope, linking the historical violence of the Middle Passage with a new oceanic threat -- plastic. The mass disposability of the rubber ducks reveals how the ocean is not only the source of history and culture but is increasingly tied to "contemporary capital's flow of commodities [through] large ocean-going container ships" (Rice 2017, 255). Indeed, "ninety percent of the world's goods $[\ldots]$ still travel $[\ldots]$ in container ships" (Yaeger 2010, 523). For Patricia Yaeger, the perpetual flow of commodities across the ocean has shaped our understanding of the ocean as a site of economic rather than ecological relation, to the extent that our "late-capitalist seas are becoming more techno than ocean" (527).

The yellow bodies of rubber ducks have been found in various pieces of contemporary Scottish Literature within recent years, arriving on the shores of Shetland in the works of Jen Hadfield, or the beaches of the Monach Islands in the works of Kathleen Jamie. Throughout her 2008 collection Nigh-No-Place, Hadfield explores local and global dimensions of place through a range of marine materials that draw attention to narratives of "capitalist excess and oceanic circulation" (Yaeger 2017, 166) in the Atlantic. Poised between land and sea, local 
and global, nature and culture, in Hadfield's works the littoral zones of the Shetland archipelago become akin to Yaeger's conception of the "quasi-ocean", a space that is "neither quite nature nor quite society; neither the opposite of the land nor a realm that is unknowable, mute, eternal, or mythic, the quasi-ocean becomes a locus for 'collecting associations of humans and nonhumans' in an awkward common world" (Yaeger 2017, 169). In "Snuskit", whose title is taken from a Shetlandic term for a "sulky frame of mind", Hadfield explores this "awkward common world" through a range of waste materials that wash ashore:

The shore is not nice. Good. The hashed basalt is black and all the rubberduckery of the Atlantic is blown up here - a bloated seal and sometimes skull, fishboxes and buoys, a cummerbund of rotting kelp. The wind topples me, punches me gently into a pool. Beyond, strafed with hail, the sea teems like TV, with frayed aerial. I step back onto my tuffet, boots pooled in buttery light. The wind punches me gently into a pool. I'm doing my best impression of a gull - pesky, pitied, lonely, greedy, hopping up and down on my tuffet. The wind punches me gently into a pool. $(2008,39)$

In a similar form to Glissant's essay “The Black Beach”, Hadfield's description of the harsh "hashed basalt" of the "black" coast creates a discomforting and polluted environment that seems unwelcoming to visitors. Continually punched by wind and wave, the poetic figure navigates an islandscape that is strewn with both local and global fragments of marine waste and encounters a world "riddled with the strange facts of human and nonhuman agency" (Yaeger 2017, 169). While the seal skull, kelp, fishboxes and buoys retain a sense of local place-attachment, invoking the fishing 
industry of Shetland, the term "rubberduckery of the Atlantic" invokes the transatlantic voyage of the Friendly Floatees, opening the beachscape to wider transnational flows of marine waste.

Nestled amongst the more localized flotsam of the Shetland archipelago, the bright body of the rubber duck is incongruous and surreally malevolent. Whereas the other materials will decay over time, as the seal carcass becomes bone and the kelp rots, the plastic buoys, fishboxes and rubber duck will remain. In her blog Rogueseeds, Hadfield voices her anxiety surrounding the accumulation of plastics within marine bodies:

Tonnes of bladderwrack washed up onto my local beach after Storm Abigail, full of smithereened plastic. In 40mph winds, I struggled along to another beach to watch the waves. I found the carcass of a young swan, a seal, and an unidentified marine mammal, perhaps a porpoise. Its skin was flensed away, and the blubber beneath was a mosaic of little chips of broken plastic. It's almost impossible to get your head around how much of this stuff is out there, chugging around the gyres like a great oceanic washing machine. We've got to sort this. (2015, n.p.)

Whereas in Caribbean poems the hurricane brings with it a swell of submerged historical materials, here the storm reveals nothing more than the polluted bodies of the marine environment. The description of the "mosaic of little chips of broken plastic" that lie within the bodies of an unidentifiable sea creature echoes the work of visual artist Chris Jordan, whose 2009 project "Midway" displays "the painful contrast between the muted browns and grays of the decomposing bodies [of albatrosses on the Midway Atoll], and the eerily cheery, super-colorful bits of plastic, predominantly bottle caps -- the banal but persistent detritus of consumerism" (Alaimo 2017, 130). Hadfield's fascination with the endurance of plastic 
reveals a sinister element to these seemingly benign materials, as objects previously used for play and entertainment become "the stuff of horror and destruction; these effects are magnified by the strange jumbling of scale in which a tiny bit of plastic can wreak havoc on the ecologies of the vast seas" (Alaimo 2017, 130). The "strange jumbling" of scale evident across Hadfield's work is not only apparent in relation to the actual size of plastic waste, or the scale of its dispersal across the oceans, but is also "strange" in a temporal sense, where the continued accumulation and recycling of plastics within marine bodies means that a single "bottle cap -- such a negligible bit of stuff to humans -- may persist in killing birds and fish for hundreds (thousands?) of years" (Alaimo 2017, 130). This perpetual sequence of surfacing and recycling reveals the uncanny agency of plastic waste, where its ingestion and regurgitation through the bodies of marine mammals reveals plastic to be a "manifestation of dark matter that has returned to haunt us, a ghost of its former useful self, but with new unfolding oracular powers" (Longobardi 2014, 189).

In a similar form, the uncanny durability and endless disposability of plastic emerges as a core concern for Kathleen Jamie in her essay "Findings", in which the bodies of discarded animals are frequently juxtaposed with the permanency of plastic objects. Across the course of the essay Jamie encounters and collects a multitude of objects at the shoreline:

Here in the rain, with the rotting whale and the wheeling birds, the plastic floats and turquoise rope, the sealskins, driftwood and rabbit skulls, a crashed plane didn't seem untoward. If a whale, why not an aeroplane? If a lamb, why not a training shoe? Here was a baby's yellow bathtime duck, and here the severed head of a doll. $(2005,60)$

Across the essay the local dimensions of here are frequently punctuated by plastics that have become unmoored from their original locus somewhere over there out across the Atlantic. 
While the opening half of the essay addresses the valuation of organic materials in the form of whale bones, quartz orbs and bird skulls, the finding of a plastic doll's head, with her uncanny "sea-blue blinking" eyes, prompts Jamie to reconfigure her valuation of materials:

I wondered if it's still possible to value that which endures, if durability is still a virtue, when we have invented plastic, and the doll's head with her tufts of hair and rolling eyes may well persist after our own have cleaned down to bone. $(2005,67)$

The juxtaposition of plastic and bone is significant here as Jamie's exploration of the durability of plastic responds to the essay's preface taken from the works of the Orcadian poet, George Mackay Brown: "Bone is subtle and lasting" (quoted in Jamie 2005, 41). There are synergies here with the work of Brathwaite and Walcott, who similarly invest bone with a "lasting" force. In Walcott's "The Sea is History", the fusion of "bone soldered by coral to bone" $(2014,253)$ reveals the seabed to be littered with the preserved relics of human history that have since become absorbed into the marine landscape. Yet when plastics outlast bone, human history is no longer attached to the image of "fossil's bone" but is instead tethered to the non-biodegradable bodies of plastic dolls and rubber ducks. Whereas previously bones bore "the fetish of our worship" (Brathwaite 1995, 11), in the age of late-capitalism our histories have become attached to the deep futures of marine plastics which surface across the techno-ocean as "both supreme commodity fetish and siren of grave consequences $[\ldots]$ both waste material and future fossil" (Longobardi 2014, 189; emphasis in original).

In Jamie's 2012 collection The Overhaul, these "future fossils of the Anthropocene" (Longobardi 2014, 189) emerge in the form of a weird plastic wilderness at the edge of Scottish beaches. In "The Beach" the surfacing and arrival of plastics onshore makes visible the un-locatable and otherwise invisible offshore movements of these marine pollutants. 
Interestingly, the encounter with waste in the poem -- the image of heaped plastic rope that is "cut loose" and forcibly "thrown back at us" from the ocean -- inverts the anthropocentric act of disposal (Jamie 2012, 3). Nondescript and severed from any identifying features, the rope that is expelled from the waves incites the speaker to pause in disbelief, or perhaps embarrassment, declaring "us - / What a species -" (3). The move from the singular lyrical "I" to the inclusive taxonomy of "species" broadens the scale of responsibility in the poem, acknowledging the culpability of the entire human race in the production and prevalence of plastic waste (3).

Yet it is not only human beings that are implicated in the continued circulation of plastics. For example, in "Materials" plastic waste begins to be incorporated into the habitat of seabirds. Noting the "scraps of nylon fishing net" that wind across the seascape, "Materials" focuses on the few remaining gannets who in winter deign to "pluck such rubbish from the waves, then / hie awa' / to colonies", embedding the nylon strands into their “swagged" nests (Jamie 2012, 50). Taking the place of "threads of moss fleeing a nor'wester", the plastic threads are recycled into the dwelling sites and habitats of seabirds, becoming just one more building material taken from the coastal landscape (50). Much like Hadfield's supplanting of seabirds with the "rubberduckery of the Atlantic", so Jamie's description of the gannets' incorporative recycling of plastic into the "natural" seascape produces a weird plastic wilderness that reflects the uncanny futurity and ubiquity of waste. The nests may decay over time, but the plastic will remain adorning the cliffs like a "shoddy bird-knitted vest" (50). The poem brings with it an ominous recognition that the things we deign to leave behind will last for centuries, where "birds, like good environmentalists, will 'reuse' these bits of plastic" for generations to come (Alaimo 2017, 130).

Across these poems, the continued construction of the ocean as both a dumping ground and transportation medium reveals how in the realm of "late capitalism, all of nature, 
including the ocean, has been endowed with exchange value" (Yaeger 2017, 167). Whereas in Caribbean poetry the acts of accumulation, salvage and exchange are imbued with a restorative and productive force, the works of Jamie and Hadfield reveal how in the context of the capitalist techno-ocean these actions are no longer aligned with a constructive economy of cultural production but are instead symptomatic of the global networks of pollution and commodity production that position the Atlantic Ocean as both a resource and medium of exploitation. In the work of Jamie and Hadfield, the accumulation of marine waste does not signify history but futurity; a damaging and precarious futurity shaped by the flows of plastics and toxics that will circulate within our oceans for millennia to come.

\section{Conclusion: An oceanic imaginary}

Across both sides of the Atlantic, relationships with the ocean are increasingly important for poets attempting to navigate new modes of relation in a changing world. Presenting a poetics that is driven by experiences of migration and displacement, of dispersal and disposal, for all of the poets examined here the fluidity of the archipelago provides the means through which to foster new connections with one another, and with the wider nonhuman world. As the works of Glissant, Brathwaite and Walcott have shown, thinking with the archipelago necessarily entails the production of new forms of relation that are plural, connective and constantly on the move. Their respective configurations of the Caribbean as a space linked through the circulation of history, economy and waste positions the archipelago as a timespace of cross-cultural connection in which history is encountered through a range of material objects washed ashore. Through an attendant poetics of salvage and recycling, their works give rise to a new environmental ethics of relation that is directly influenced by encounters with the ocean. Their engagement with the dynamics of submersion and dispersal are not only deeply cultural and historical but are increasingly ecological in their attention to the type 
of materials that wash ashore. Indeed, their particular model of archipelagic interconnection, in which salvage and restoration is central to questions of identity and relation, has come to influence other modes of artistic practice such as those present in the work of the visual artist Tony Capellán, whose exhibition "The Poetics of Relation” at the Pérez Art Museum in Miami in 2015 explored the "historical legacy of trauma caused by colonialism and migration" (http://www.pamm.org/exhibitions/poetics-relation) through two large-scale installation pieces titled "Mar Caribe" and "Mar Invadido", which are crafted from found plastics salvaged from the Caribbean sea. Using objects such as foam flip-flops, plastic bottles and deodorant containers to recreate the colours of Caribbean seascapes, these artworks not only highlight the beauty and precarity of marine environments but work to "build stories, metaphors, and visions about the reality" of those disposable persons, the "marginalized and poor families" who live along the polluted riverbanks of the Dominican Republic (Capellán 2015). As I have shown, in the Scottish context these marine plastics not only carry the residual traces of transatlantic history, but actively link together contemporary stories of production, exploitation and pollution that circulate across the global ocean. In drawing attention to submarine narratives of wasted lives and waste materials, the work of Scottish and Caribbean poets effectively relocates the human subject within global networks of responsibility and culpability, and in so doing actively considers alternative modes of oceanic relation that are based upon environmental principles of salvage and recovery.

\section{Notes}

${ }^{1}$ The term includes the islands of "Great Britain (England, Scotland, Wales), Ireland (Northern Ireland and the Republic of Ireland), the Isle of Man, the Hebrides, the Orkney Isles, the Shetland Islands, the Isles of Scilly, and the Channel Islands" (Oxford English Dictionary). 
${ }^{2}$ For a more in-depth discussion of the "forgotten history of Scottish involvement in the Atlantic slave trade", see Morris (2015).

3 “Gilles Deleuze and Felix Guattari criticised notions of the root and, even perhaps, notions of being rooted. The root is unique, a stock taking all upon itself and killing all around it. In opposition to this they propose the rhizome, an enmeshed root system, a network spreading either in the ground or in the air, with no predatory rootstock taking over permanently. The notion of the rhizome maintains, therefore, the idea of rootedness but challenges that of a totalitarian root. Rhizomatic thought is the principle behind what I call the Poetics of Relation, in which each and every identity is extended through a relationship with the Other" (Glissant 1997, 11).

${ }^{4}$ Bloomfield (2016) notes how "Brathwaite has often been positioned - and has positioned himself - in contrast to the poetic stance of St. Lucian poet Derek Walcott. The well-worn dichotomy of Brathwaite, cast as the iconoclastic vernacular creole poet, and Walcott, seen as the ironic mimic of traditional literary forms, as the polar opposites of Caribbean poetry has been quite rightly contested by recent criticism" (152).

\section{Notes on contributor}

Alexandra Campbell is an Early Career Researcher and Teaching Fellow in English Literature at the University of Edinburgh. Her research emerges at the intersection of several critical discourses, including critical ocean studies, the environmental humanities and world literature perspectives. She is particularly interested in ecologies and poetries of the sea and is currently working on her first monograph which examines poetic responses to oceanic resource exploitation in North Atlantic writing, focusing on discourses of extraction, disposal and transmission at sea.

\section{References}

Alaimo, Stacy. 2012. "States of Suspension: Transcorporeality at Sea.” ISLE 19 (3): 476493.

Alaimo, Stacy. 2017. Exposed: Environmental Politics and Pleasures in Posthuman Times. Minneapolis, MN: Minnesota University Press. 
Bloomfield, Mandy. 2016. Archaeopoetics: Word, Image, History. Tuscaloosa, AL: University of Alabama Press.

Brathwaite, Kamau. 1981. The Arrivants: A New World Trilogy. Oxford: Oxford University Press.

Brathwaite, Kamau. 1995. Black+Blues. New York: New Directions.

Capellán, Tony. 2015. "Watch Artist Tony Capellán Discuss his Works in the Exhibition 'Poetics of Relation'.” Pérez Art Museum Miami, May 29. https://www.youtube.com/watch?v=zT5WnhJqx9A.

DeLoughrey, Elizabeth. 2010. "Heavy Waters: Waste and Atlantic Modernity.” PMLA 125 (3): 703-712.

DeLoughrey, Elizabeth. 2012. "Island Writing, Creole Cultures.” In The Cambridge History of Postcolonial Literature, edited by Ato Quayson, 802-832. Cambridge: Cambridge University Press.

Döring, Tobias. 2015. "Caribbean Beachcombers." In The Beach in Anglophone Literatures and Cultures, edited by Ursula Kluwick and Virginia Richter, 107-121. Farnham: Ashgate.

Glissant, Édouard. 1989. Caribbean Discourse. Translated by J. Michael Dash. Charlottesville, VA: University of Virginia Press.

Glissant, Édouard. 1997. The Poetics of Relation. Translated by Betsy Wing. Ann Arbor, MI: University of Michigan Press.

Hadfield, Jen. 2008. Nigh-No-Place. Hexham: Bloodaxe Books.

Hadfield, Jen. 2013. A Highland Romance: Victorian Views of Scottishness. Poems Commissioned by the Manchester Literature Festival. Manchester: Manchester Art Gallery. http://www.manchesterliteraturefestival.co.uk/downloads/3173c6g8s6tsx.pdf?f=a-highland-romance-by-jen-hadfield 
Hadfield, Jen. 2015. "This Is What is in the Ocean." Rogueseeds, November 15. http://rogueseeds.blogspot.co.uk/2015/11/this-is-what-is-in-ocean-15111.html.

Jamie, Kathleen. 2005. Findings. London: Sort of Books.

Jamie, Kathleen. 2012. The Overhaul. London: Pan Macmillan.

Kerrigan, John. 2008. Archipelagic English. Oxford: Oxford University Press.

Longobardi, Pam. 2014. "Plastic as Shadow: The Toxicity of Objects in the Anthropocene." In Framing the Ocean, 1700 to the Present: Envisioning the Sea as Social Space, edited by Tricia Cusack, 181-195. Farnham: Ashgate.

Miller, Kei. 2008. "But in Glasgow There Are Plantains.” International Journal of Scottish Literature 4: 1-6. http://www.ijsl.stir.ac.uk/issue4/millerOP.htm.

Miller, Kei. 2014. The Cartographer Tries to Map a Way to Zion. Manchester: Carcanet Press.

Morris, Michael. 2015. Scotland and the Caribbean, C.1740-1833: Atlantic Archipelagos. London: Routledge.

Naylor, Paul. 1999. Poetic Investigations: Singing the Holes in History. Evanston, IL: Northwestern University Press.

Oxford English Dictionary, s.v. "British Isles.” Accessed June 5, 2017. http://www.oed.com/ Pocock, J.G.A., ed. 2005. The Discovery of Islands: Essays in British History. Cambridge: Cambridge University Press.

Postmentier, Sonya. 2017. Cultivation and Catastrophe: The Lyric Ecology of Modern Black Literature. Baltimore, MD: Johns Hopkins University Press.

Rice, Alan. 2017. "Of Plastic Ducks and Cockle Pickers: African Atlantic Artists and Critiques of Bonded Labor across Chronologies." In Migrating the Black Body: The African Diaspora and Visual Culture, edited by Leigh Raiford and Heike RaphaelHernandez, 253-266. Seattle, WA: University of Washington Press. 
Scottish Book Trust. n.d. “Author Details: Kei Miller.” Accessed November 24, 2017. http://scottishbooktrust.com/profile-author/69447.

Walcott, Derek. 1992. “The Antilles: Fragments of Epic Memory.” Nobelprize.org. http://www.nobelprize.org/nobel_prizes/literature/laureates/1992/walcottlecture.html.

Walcott, Derek. 2014. The Poetry of Derek Walcott 1948-2013. New York: Farrar, Straus and Giroux.

Yaeger, Patricia. 2010. "Sea Trash, Dark Pools, and the Tragedy of the Commons." PMLA 125 (3): 523-545.

Yaeger, Patricia. 2017. "The Ocean as Quasi-Object, or Ecocriticism and the Doll from the Deep.” In The Sea and Nineteenth-Century Anglophone Literary Culture, edited by Steve Mentz and Martha Elena Rojas, 166-185. London: Routledge. 